Article

\title{
Equine-Assisted Interventions (EAIs) for Children with Autism Spectrum Disorders (ASD): Behavioural and Physiological Indices of Stress in Domestic Horses (Equus caballus) during Riding Sessions
}

\author{
Laura Contalbrigo $^{1, *(\mathbb{D}}$, Marta Borgi ${ }^{2} \mathbb{D}$, Marta De Santis ${ }^{1} \mathbb{D}$, Barbara Collacchi ${ }^{2} \mathbb{D}$, Adele Tuozzi $^{2}$, Marica Toson ${ }^{1}$, \\ Veronica Redaelli $^{3}{ }^{\mathbb{D}}$, Rosangela Odore ${ }^{4}$, Cristina Vercelli ${ }^{4} \mathbb{D}$, Annalisa Stefani ${ }^{1,+} \mathbb{D}$, Fabio Luzi $^{3,+}$, \\ Emanuela Valle ${ }^{4,+}+\mathbb{D}$ and Francesca Cirulli ${ }^{2,+}$ \\ 1 Istituto Zooprofilattico Sperimentale delle Venezie, Viale Dell’Università, 10, 35020 Legnaro, Italy; \\ mdesantis@izsvenezie.it (M.D.S.); mtoson@izsvenezie.it (M.T.); astefani@izsvenezie.it (A.S.) \\ 2 Centre for Behavioural Sciences and Mental Health, Istituto Superiore di Sanità, Viale Regina Elena 299, \\ 00161 Rome, Italy; marta.borgi@iss.it (M.B.); barbara.collacchi@iss.it (B.C.); adele.tuozzi@gmail.com (A.T.); \\ francesca.cirulli@iss.it (F.C.) \\ 3 Department of Biomedical, Surgical and Dental Sciences-One Health Unit, Via Pascal, 36, \\ 20133 Milano, Italy; veronica.redaelli@unimi.it (V.R.); fabio.luzi@unimi.it (F.L.) \\ 4 Department of Veterinary Sciences, University of Torino, Largo P. Braccini 2, 10095 Grugliasco, Italy; \\ rosangela.odore@unito.it (R.O.); cristina.vercelli@unito.it (C.V.); emanuela.valle@unito.it (E.V.) \\ Citation: Contalbrigo, L.; Borgi, M.; \\ De Santis, M.; Collacchi, B.; Tuozzi,
} A.; Toson, M.; Redaelli, V.; Odore, R.; Vercelli, C.; Stefani, A.; et al. Equine-Assisted Interventions (EAIs) for Children with Autism Spectrum Disorders (ASD): Behavioural and Physiological Indices of Stress in Domestic Horses (Equus caballus) during Riding Sessions. Animals 2021, 11, 1562. https://doi.org/10.3390/ ani11061562

Academic Editors: Sue M. McDonnell and Lucia Francesca Menna

Received: 28 April 2021

Accepted: 22 May 2021

Published: 27 May 2021

Publisher's Note: MDPI stays neutral with regard to jurisdictional claims in published maps and institutional affiliations. 
increase their awareness of animal welfare and refine riding practices, taking into account horse's needs.

Keywords: equine-assisted interventions; horse; autism; infrared thermography; behaviour; heart rate; heart rate variability; welfare; cortisol; catecholamines

\section{Introduction}

Equine-assisted interventions (EAIs) are gaining increasing attention as complementary practices for the rehabilitation of persons with mental and physical disabilities [1,2]. These interventions combine physical activity with emotional/cognitive elements and such a combination has made these programmes suitable for rehabilitation programmes targeting children in need of a high degree of stimulation, such as children with autism spectrum disorders (ASD) [3-5]. Positive effects of EAIs include improvements in areas of functioning known to be impaired in ASD. The most affected areas are social responsiveness and motivation, language/communication, stress behaviours (e.g., irritability and hyperactivity), motor functioning, and sensory processing [6-12]. Although the involvement of animals in ASD rehabilitation programmes has become a common practice (an estimated one in four children with ASD has participated in animal-assisted interventions) [13], the response of animals when interacting with subjects with social and emotional problems-like those diagnosed with ASD—have not been sufficiently investigated. There is preliminary evidence suggesting that horses are sensitive to riders' behaviours, especially when the rider has emotional or behavioural problems [14]. Some studies show that their relational style and conflicting orders may cause distress to the horse $[15,16]$ which is potentially associated with long-term detrimental health and behavioural effects [17]. As an example, inconsistent application of communicative signals can cause confusion and conflict-related behaviours in horses, with possible negative consequences for their welfare, as well as for human safety [18-20].

As far as we know, no studies have so far examined horses' reaction to EAI sessions with children diagnosed with ASD, whose core symptoms affect their relational and communicative behaviour, often showing impulsivity, hyperactivity, and aggressiveness [21,22].

Within this framework, our study aimed to investigate behavioural and physiological indices of stress in horses involved in EAI sessions with children with ASD versus typically developing children to appraise which activities and interactions cause more discomfort in the animal. Stress-related behaviours during the sessions were recorded concurrently with measures of physiological functions such as heart rate, heart rate variability, and eye temperature, which are known to provide insight into responses of the autonomic nervous system (ANS) in a range of physiological and pathological conditions [23-26]. Moreover, changes in blood ACTH, cortisol, and catecholamines were assessed before and after each session. The use of non-invasive techniques, such as infrared thermography and heart rate monitoring, to collect physiological data during riding sessions has the advantage that it does not interfere with the spontaneous child-horse interaction and minimizes the stress caused by classic sampling procedures.

\section{Materials and Methods}

\subsection{Ethical Statement}

The methods and procedures of this study were in accordance with Italian legislation (D.L.vo n. 26 of 4 March 2014) on the protection of animals used for scientific purposes (Authorization $n^{\circ} 1055 / 2015-\mathrm{PR}$ ). Owners of horses gave written consent to the enrolment of their animals in the study. Moreover, children's parents signed informed written consent for the involvement of their children in riding sessions, and all data about their children were processed in compliance with privacy and data protection law. The research protocol was approved by the Ethics Committees of the Istituto Zooprofilattico Sperimentale delle 
Venezie (EC protocol number 6/2014) and the Istituto Superiore di Sanità (Prot. PRE$790 / 15)$.

\subsection{Horses}

Nineteen horses of different ages (mean $17.3 \pm 5.7$ years), sex (six mares and thirteen geldings), and breed (4 Italian saddles, 8 ponies, 3 Argentine, 1 Maremmano, 1 Haflinger, 1 Wielkopolski, and 1 Hungarian) were recruited from 4 Italian Riding Centres. We collected data about their long-term and recent anamnesis, training procedures, and weekly workload. All horses were suitable for morphology and biomechanics; they were in good health without signs of injuries, sickness, or disease and they didn't show abnormal behaviours and stereotypes. They were involved in a $1 \mathrm{~h}$ EAI session and $2 \mathrm{~h}$ of riding school each day. All of them were trained for EAI using operant conditioning with positive reinforcement, without punishment and coercive methods. They had an average of 5 years of experience in EAIs. All horses were normally group-housed in the paddock during the day and they spent the night in an individual box. They have free access to water. The pasture was supplemented with hay and additional horse feed twice a day. Husbandry practices, veterinary care, and grooming of horses in the four riding centres were similar.

\subsection{Human Subjects}

Thirty-eight children, aged 6-12 years, were involved in the study: 19 with a previous ASD diagnosis and 19 typically developing (TD) children. Children were selected among those who attended the riding centres participating in the study. All children had a similar experience with horses: less than one year. Exclusion criteria were horse allergy and/or fear.

\subsection{Study Design}

This multicentre study followed a controlled within-subject design with repeated measurements. Each horse was involved in two different riding sessions:

1. An equine-assisted session with the horse ridden by a child with ASD (ASD session).

2. Control session with the horse ridden by a TD child (TD session).

Horses were randomly assigned to a child with ASD and a TD child using a predetermined randomised order generated in Microsoft Excel. Sessions were carried out on two consecutive days. The order of ASD session and TD session was counterbalanced among subjects. To reduce bias due to the environment and the circadian/circannual effects, all sessions were performed in the afternoon (between $2 \mathrm{pm}$ and $4 \mathrm{pm}$ ) during the winter season (November 2015-January 2016).

\subsection{Setting}

ASD and TD sessions were carried out outside, in a quiet environment. Each riding centre had a fenced area assigned to EAIs and riding sessions with soft and well-drained soil. Sessions were carried out by professionals with good knowledge of each horse. In each riding centre, the same team was involved in all sessions. It was composed of a horse handler and a therapist who was in charge of the ASD child or the TD child during the whole session, according to Italian National Guidelines for Animal-assisted interventions [27]. Both ASD and TD sessions followed a standardised procedure (adapted from Borgi and colleagues [3]). They lasted about $30 \mathrm{~min}$ and followed the protocol described in Table 1. 
Table 1. Session description: phases and their duration and activities performed.

\begin{tabular}{|c|c|c|}
\hline Phase & Duration (min) & Description of the Activity and Main Goals \\
\hline Grooming & $5^{\prime}$ & $\begin{array}{l}\text { Child's approach to the horse and first contact; child's knowledge of the horse } \\
\text { (morphology, behaviour); main security rules; grooming techniques (brushing } \\
\text { the body of the horse) and saddling }\end{array}$ \\
\hline Horse at hand & $5^{\prime}$ & The child leads the horse with a lead rope around the arena \\
\hline Mounting & - & The horse stops and the child mounts the horse \\
\hline Riding exercises & $10^{\prime}$ & $\begin{array}{l}\text { Learning riding basic elements (walk). Performing exercises while riding the } \\
\text { horse (rotating/bending, outstretching upper arms and trunk) }\end{array}$ \\
\hline Stationary exercises & $5^{\prime}$ & $\begin{array}{c}\text { Performing exercises on the horse (horse halted). Games such as rods, cones, } \\
\text { or balls are used }\end{array}$ \\
\hline Closing & $5^{\prime}$ & Riding the horse around the arena \\
\hline Dismounting & - & The horse stops and the child dismounts \\
\hline Reward & - & The child rewards the horse (e.g., carrot, sugar, hay, etc.) \\
\hline
\end{tabular}

\subsection{Experimental Procedure}

The experimental procedure is plotted in Figure 1, which provides a detailed description of collection methods of physiological and behavioural data from the horses enrolled in the study.

\begin{tabular}{|l|l|}
\hline SAMPUING METHOD & TIME \\
\hline Blood and saliva collection & $10^{\prime}$ before and $10^{\prime}$ after the session (PREL: sampling) \\
\hline Behavioural analysis & Videorecording during the whole session \\
\hline Infrared termography & $\begin{array}{l}\text { Videorecording during the whole session, frames taken at specific timepoints as illustrated in the } \\
\text { timeline below (BAS: baseline; GROOM: grooming; START: mounting; LAV: riding exercises; ALT: } \\
\text { stationary exercises; END: reward) }\end{array}$ \\
\hline Heart rate monitor & Application during the whole session (from 5' before to 5' after the session) \\
\hline
\end{tabular}

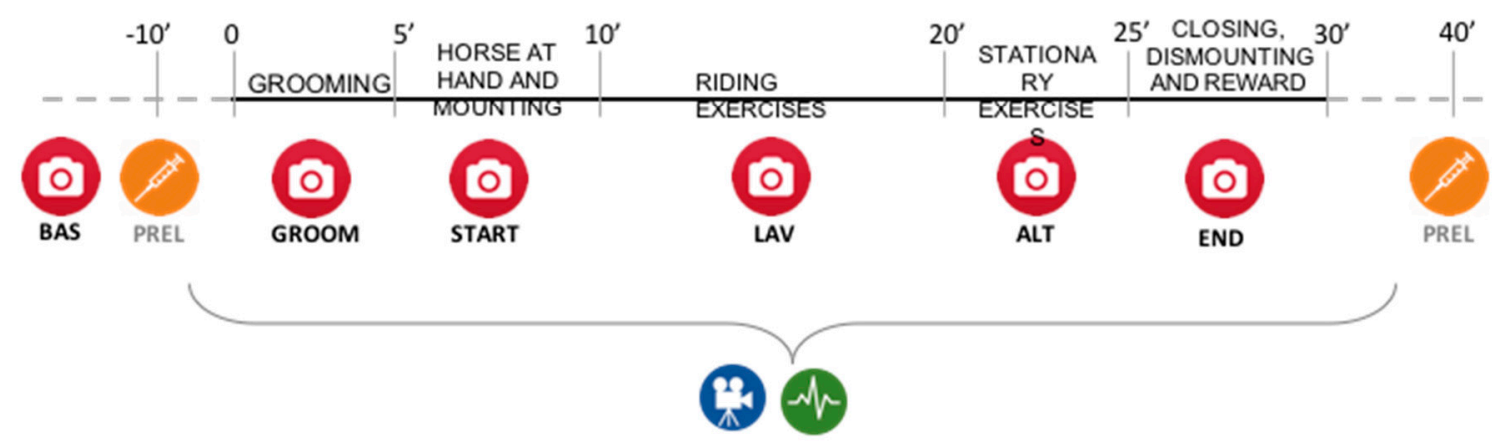

Figure 1. Sampling protocol adopted in the study.

\subsubsection{Blood Sampling}

Blood samples were collected using jugular venipuncture [28] ten minutes before $\left(-10^{\prime}=\mathrm{T} 0\right)$ and ten minutes after the end of each session $\left(40^{\prime}=\mathrm{T} 1\right)$ to measure serum cortisol, plasma ACTH, and catecholamines-adrenaline, noradrenaline, and dopamine. Blood was collected with the horse standing in his box. We used K3EDTA tubes to get plasma and tubes without anticoagulants for serum. We centrifuged the K3EDTA tubes immediately after the collection whereas blood without anticoagulant was allowed to clot for $30 \mathrm{~min}$ in a vertical position. After centrifugation, each plasma sample was shared in 4 aliquots and 
serum in one tube. All samples were stored at $-20^{\circ} \mathrm{C}$ immediately. Afterward, samples were sent to the laboratory with a shipment in dry ice. Serum cortisol and plasma ACTH were analysed using the Immulite ${ }^{\circledR a u t o m a t e d ~ c h e m i l u m i n e s c e n c e ~ i m m u n o a s s a y ~ s y s t e m ~}$ already validated for horse cortisol [29,30] and ACTH [31,32]. Plasma catecholamines (adrenaline, noradrenaline, and dopamine) were analysed using the CatCombi ELISA kit (IBL International $\mathrm{GmbH}$ ). This kit allows the use of plasma from many animal species, including horses, since catecholamines have the same chemical structure in all animals and the catecholamine assays include an extraction step at the beginning of the procedure [33].

\subsubsection{Behavioural Analysis}

All 38 sessions (19 ASD sessions and 19 TD sessions) were video-recorded with two Sony cameras (Handycam DCR-SX21E, Sony Europe B.V.The Heights, Brooklands, Weybridge, Surrey, KT13 0XW, United Kingdom)). The ethogram was developed in order to identify stress-related or discomfort behaviours in horses, such as snorting, pawing, headshaking, head-tossing, as well as redirected activities indicating a conflict in the animal, such as oral manipulation and nodding [15,34-41]. All behaviours considered are listed in Table 2. Behavioural analysis was performed using a focal sampling method [42] and dedicated software (BORIS, Università degli Studi di Torino, Turin, Italy) [43]. In order to improve the reliability of behavioural data, behaviours were scored independently by two raters in a sub-sample of videos (13 videos of 13 different horses). An intraclass correlation coefficient (ICC) was calculated to test agreement between raters. The correlation between the two scores was positive and significant (ICC, $\mathrm{r}=0.8, p<0.05)$. After having reached the agreement, only one rater scored all videos. Behaviours were calculated as the relative frequency in each phase of the session described in Table 1: (i) grooming; (ii) horse at hand; (iii) mounting; (iv) riding exercises; (v) stationary exercises; (vi) closing (vii) dismounting; (viii) reward.

Table 2. Horse's stress-related behaviours scored during the sessions.

\begin{tabular}{|c|c|}
\hline Behaviour & Description \\
\hline Head nodding & $\begin{array}{l}\text { The horse repetitively moves its head vertically ( }>3 \text { movements up } \\
\text { and down) }\end{array}$ \\
\hline Head shaking & The horse tosses its head in sudden bouts \\
\hline Head tossing & $\begin{array}{l}\text { Head lowered with the ears pinned back interrupted with momentary } \\
\text { sharp tossing or rotating gestures of the head }\end{array}$ \\
\hline Head raised/high & $\begin{array}{l}\text { Head held higher than the normal carriage with nose extended upward } \\
\text { and with a slight extension of the neck }\end{array}$ \\
\hline Head down & $\begin{array}{l}\text { The horse held its nose below its belly-line; neck may be stretched out with } \\
\text { nose pushed forward }\end{array}$ \\
\hline Ears pinned back & Ears pressed caudally against the head and neck \\
\hline Snorting & $\begin{array}{l}\text { Forceful expulsion of air through the nostril incidentally preceded by a } \\
\text { raspy inhalation sound }\end{array}$ \\
\hline Lip play & $\begin{array}{l}\text { The horse moves its upper lip up and down without making contact with } \\
\text { an object, or the horse smacks its lips together }\end{array}$ \\
\hline Tongue play & The horse sticks out its tongue and twists it in the air \\
\hline Chomping the bit & $\begin{array}{l}\text { Any mouth or tongue manipulation of the bit independent of the rider's } \\
\text { use of the reins }\end{array}$ \\
\hline Lip/Teeth rubbing & $\begin{array}{l}\text { The horse rubs its upper lip or its upper teeth repetitively against the } \\
\text { arena wall }\end{array}$ \\
\hline Head bumping & $\begin{array}{l}\text { The horse bumps or attempts to bump its head against the side walker or } \\
\text { the instructor }\end{array}$ \\
\hline Biting leads & The horse bites or attempts to bite the side walker/instructor the lead rope \\
\hline Avoidance/Halt & $\begin{array}{l}\text { The horse stops walking; cessation of movement of all feet, or } \\
\text { backward movement }\end{array}$ \\
\hline Pawing & The horse hits the ground with the paws \\
\hline Tail swishing & $\begin{array}{l}\text { Any exaggerated movement of the tail, usually more of a wringing motion } \\
\text { than a rhythmic or directed swishing (no insect present) }\end{array}$ \\
\hline
\end{tabular}




\subsubsection{Infrared Thermography (IRT)}

Thermographic images were collected using an infrared camera (Thermo GEAR G120EX, Nippon Avionics Co., LTD, Ikonobecho, Japan). This camera has a thermal sensitivity of $0.04^{\circ} \mathrm{C}$ at $30^{\circ} \mathrm{C}$ and an accuracy of $\pm 2 \%$ between $0{ }^{\circ} \mathrm{C}$ and $40{ }^{\circ} \mathrm{C}$. Temperature measurements range between $-40{ }^{\circ} \mathrm{C}$ to $1500{ }^{\circ} \mathrm{C}$. Thermal videos were analysed through the InfRec Analyzer NS9500 Lite, a thermal image processing and report generator software (Nippon Avionics Co., LTD, Ikonobecho, Japan). The average environmental temperature was entered into the camera settings and it was a reference in each video as recommended in the literature [44]. From the videos recorded, frames with the best image quality were selected during the following phases of each session: (i) grooming; (ii) mounting; (iii) riding exercises; (iv) stationary exercises; (v) reward (see Table 1). A baseline image was recorded immediately before the starting of all experimental procedures in the same area as the sessions. All images were scanned from a distance of one metre. Temperatures of the lacrimal caruncle on both eyes of each horse were analysed with a method described by Redaelli et al., 2014 [45].

\subsubsection{Heart Rate and Heart Rate Variability}

In order to record continuously the heart rate (HR) and heart rate variability (HRV) using the beat-to-beat interval (RR), horses were fitted with a girth enabling the attachment of a Polar Equine ${ }^{\circledR}$ RS800 (Polar Electro Oy, Professorintie 5, 90440 Kempele, Finland). The girth was secured around the horse's thorax to the left-hand side girth region and the electrodes were moistened with abundant transmission gel to improve the horse skin and coat conductance to maximize data recording accuracy. A heart rate monitor was fitted $5 \mathrm{~min}$ before the session started and removed $5 \mathrm{~min}$ after the end of the session. At the end of each session, the stored data were downloaded onto a computer through an infrared port (IrDa) for storage and later analysis. Data were analysed with Polar ProTrainer 5 software. The graphs were evaluated visually and corrected in case of too high or low peaks, or flat lines (plateau), considering a percentage of errors identified that did not exceed $6 \%$ as recommended in the literature [46]. HR and its oscillations (high-frequency band-HF, low-frequency band-LF, very low frequency band-VLF, $\mathrm{LF} / \mathrm{HF}$ ratio), the standard deviation of RR interval (SDRR) and root mean square of successive RR differences (RMSSD) were calculated from the RR interval. For each phase of the sessions (see Table 1), these parameters were expressed as means and submitted to statistical analysis.

\subsection{Statistical Analysis}

Data were analysed using STATA 12.1 and SAS 9.4. We analysed hormonal (ACTH, cortisol, and catecholamines) differences between pre vs post-session using the Wilcoxon test for paired data and we investigated significant differences between ASD and TD sessions by sign test for paired data. Physiological (infrared thermography and heart rate and heart rate variability data), as well as behavioural parameters, were analysed using the Wilcoxon test for paired data.

Multivariate analysis was performed using a linear mixed-effect model (LMM) using SAS 9.4 (PROC MIXED). This statistical model, containing both fixed effects and random effects, is very useful for repeated measurements on the same statistical units, as in our case [47]. Dependent variables included data from behavioural analysis, thermographic images, and heart rate monitor while explanatory variables included horse features (sex, age, experience), sessions (ASD vs. TD), and session phases. Horse age and experience were categorised considering median values (2-5 years vs. 6-14 years of experience in EAI). We included a random effect due to horse and the variance components were chosen as the best covariance structure. The normality of the residuals was checked using a normal probability plot. Post-hoc analysis was performed using adjusted $p$-value for multiple comparisons using Dunnett's T3 method [48]. For the fixed effect, the denominator degrees of freedom are determined from a Satterthwaite approximation. 


\section{Results}

\subsection{ACTH, Cortisol, and Catecholamine}

ACTH, cortisol, and catecholamines were within the physiological range in horses [49-51]. Plasma adrenaline, noradrenaline, dopamine, and ACTH responses to exercise were highly and positively correlated $\left(\mathrm{rho}_{\mathrm{s}}>0.7 ; p<0.05\right)$ as described in the literature [52]. We considered the delta (T1-T0) and we used the Sign test to investigate differences between ASD and TD group. No differences were found in ACTH, cortisol, noradrenaline, and dopamine between the two groups (ASD vs. TD), while horses showed a significantly smaller increase of plasma adrenaline concentration in ASD sessions compared to TD sessions $(p$-value $<0.05)$ (Figure 2).

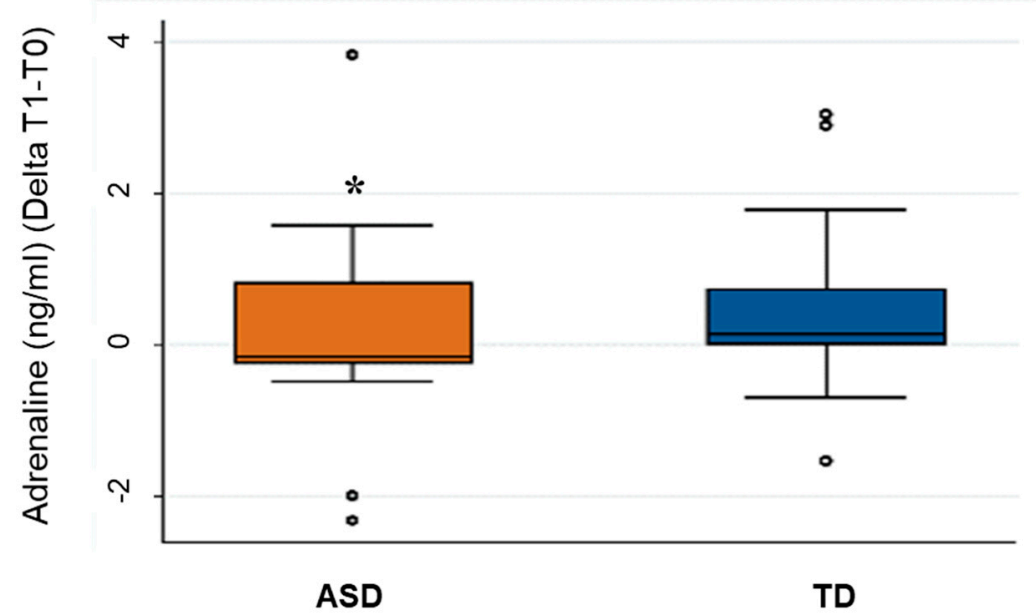

Figure 2. Differences (T1-T0) for adrenaline (ng/mL) in ASD and TD session. The figure shows the upper and lower quartiles (box), medians (horizontal line in the box), minimum and maximum values (whiskers), and outliers (individual points); ${ }^{*} p<0.05$.

\subsection{Behaviour Analysis}

Multivariate analysis on 19 horses using the LMM model showed no significant differences between sessions (ASD vs. TD), but only among different phases (see Type III Tests of Fixed Effects in Table 3, Figure 3). Post-hoc analysis pointed out a significant increase in stress-related behaviour frequency between mounting and dismounting phases compared to "horse at hand" ( $p$-value $=0.0005$ and 0.0052 respectively), "closing" ( $p$-value $=0.0028$ and 0.025), and "reward" ( $p$-value $=0.0005$ and 0.0053 respectively) and also between "mounting phase" compared to "riding exercises" ( $p$-value $=0.0383$ ). The normality of the residuals was confirmed using normal probability plots.

Table 3. Results of the Type III Tests of Fixed Effects for stress-related behaviors.

\begin{tabular}{ccccc}
\hline Effect & DFnum & DFden & F & Pr $>$ F \\
\hline Phase & 7 & 284 & 6.43 & $<0.001$ \\
Group (ASD vs. TD) & 1 & 284 & 0.52 & 0.4733 \\
Group*phase & 7 & 284 & 1.61 & 0.1327 \\
Age & 1 & 18.8 & 0.38 & 0.5434 \\
Experience (exp) & 1 & 18.8 & 1.40 & 0.2509 \\
Sex (M/F) & 1 & 18.8 & 0.10 & 0.7592 \\
Phase*age & 7 & 284 & 2.07 & 0.0468 \\
Phase*exp & 7 & 284 & 2.00 & 0.0552 \\
Phase* exp*M $_{\text {Phase*age*exp }}^{*}$ exp & 8 & 96.8 & 2.06 & 0.0475 \\
& 8 & 96.8 & 2.06 & 0.0475 \\
\hline
\end{tabular}




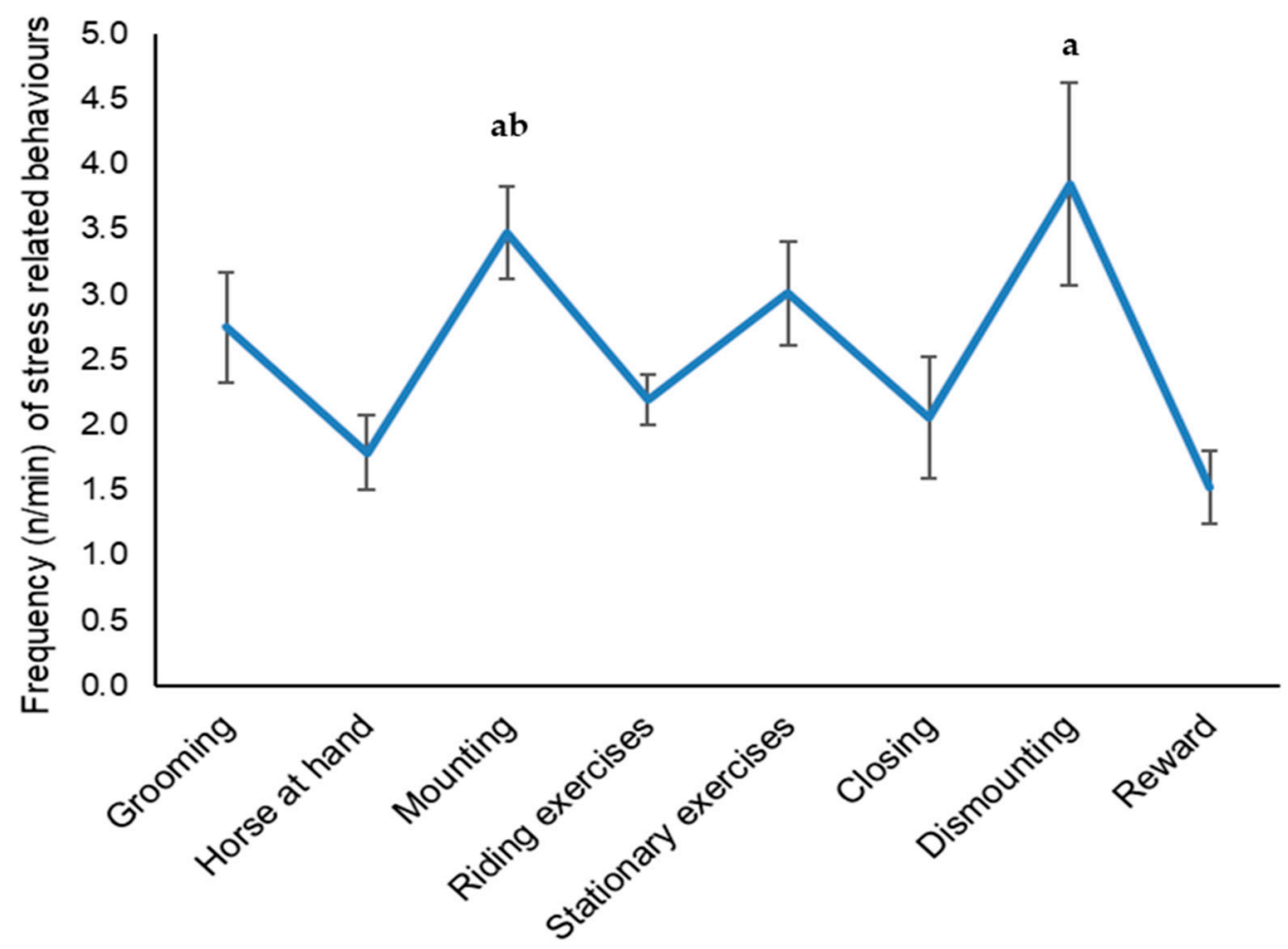

Figure 3. Frequency (n/min) of stress-related behaviours in horses in the different phases of the sessions (mean \pm SEM). a: $>$ "horse at hand, "closing", and "reward" (all ps < 0.05); b: >"riding exercises" $(p<0.05)$.

\subsection{Eye Temperature}

The LMM performed on the detected periocular temperatures, showed that there were no significant differences between sessions and phases. Residual analysis and their normality confirmed the validity of the applied mixed model. However, when we introduced the baseline eye temperature, collected before the starting of experimental procedures, ANOVA showed that there was a rise in eye temperature in the grooming phase compared to baseline in both ASD and TD sessions, but this difference became significant only in ASD sessions ( $p$-value $<0.005$ ).

\subsection{Heart Rate and Heart Rate Variability (a Subset of Horses)}

Only data from 11 horses were available for the final analysis because of interferences with the recording device. HR correlated with HRV inversely, as described in the literature [53], and HR had a physiological trend during sessions due to horse exercises with higher values during animal motor activities. The statistical analysis (LMM) pointed out significant differences among phases for HR ( $p$-value $<0.001), \mathrm{LF} / \mathrm{HF}(p$-value $<0.001)$ and RMSSD ( $p$-value $=0.0002)$, but only RMSSD showed a significant difference between ASD and TD sessions ( $p$-value $=0.0004)($ Table 4$)$. Moreover, an effect due to age and experience was found, with HR and RMSSD being significantly lower in older horses ( $\geq 18$ years old) which were also those with more than 6 years of experience in EAI. 
Table 4. Results of the Type III Tests of Fixed Effects for HR, LF/HF, RMSSD.

\begin{tabular}{|c|c|c|c|c|c|c|}
\hline \multirow{2}{*}{ Effect } & \multicolumn{2}{|c|}{ HR } & \multicolumn{2}{|c|}{ LF/HF } & \multicolumn{2}{|c|}{ RMMSD } \\
\hline & $\mathbf{F}$ & $\operatorname{Pr}>$ F & $\mathbf{F}$ & $\operatorname{Pr}>$ F & $\mathbf{F}$ & $\operatorname{Pr}>$ F \\
\hline Phase & 48.29 & $<0.0001$ & 6.76 & $<0.0001$ & 4.53 & 0.0002 \\
\hline Group (ASD vs. TD) & 1.52 & 0.2201 & 1.49 & 0.2243 & 13.42 & 0.0004 \\
\hline Group*Phase & 3.85 & 0.0008 & 0.56 & 0.7909 & 1.01 & 0.4297 \\
\hline Age & 2.76 & 0.1298 & 0.37 & 0.5566 & 7.91 & 0.0187 \\
\hline Phase*age & 4.04 & 0.0005 & 1.39 & 0.2149 & 6.38 & $<0.0001$ \\
\hline Group*age & 3.48 & 0.0643 & 1.86 & 0.1751 & 0.27 & 0.6058 \\
\hline Group*phase*age & 0.93 & 0.4836 & 0.34 & 0.9348 & 1.02 & 0.4177 \\
\hline Age*exp & 0.07 & 0.7997 & 0.01 & 0.9275 & 1.17 & 0.3055 \\
\hline Phase*age*exp & 2.58 & 0.0163 & 1.23 & 0.2894 & 0.71 & 0.6658 \\
\hline Group*age*exp & 0.10 & 0.7539 & 0.61 & 0.4370 & 0.02 & 0.8764 \\
\hline Group $^{*}$ phase*age*exp & 2.62 & 0.0147 & 0.56 & 0.7878 & 1.04 & 0.4053 \\
\hline
\end{tabular}

\section{Discussion}

Our study aimed to assess physiological and behavioural markers of stress commonly used in equitation science [54]. In particular, we aimed at integrating behavioural and physiological indices of stress during EAI sessions involving children with ASD to monitor horse welfare. Our results indicate that children with ASD do not impact the horse's welfare compared with TD children of the same age, at least during a typical riding session like the one we set up.

We considered the main products of the hypothalamus-pituitary-adrenal (HPA) axis (plasma ACTH, and serum cortisol) and of the sympathetic-adrenal medulla axis (blood catecholamines), which are activated in response to stressful stimuli [55]. Many studies have previously investigated concentrations of these metabolites in horses exposed to both positive situations, such as sexual excitement or physical exercise [56,57], and negative ones (distress) such as restraint, isolation, or transportation [58] showing significant changes, depending upon the specific stimulation they were exposed to [52]. Even though the procedure we used was highly standardised and we limited seasonal and circadian rhythm fluctuations collecting blood samples during the same period of the year (NovemberJanuary) and during the same time frame (14.00-16.00), our data showed a high degree of variability. This is expected, given the different riding centers, the different ages, and sexes of the horses involved [50], not to mention their life history. In any case, all parameters measured were well within the physiological range $[59,60]$ in the two sessions and were not affected by the rider (ASD vs. TD session) suggesting that, on average, the riding session is not a stressful situation even when the rider is a child with ASD. These findings were confirmed by other authors: Johnson et al. investigated plasma ACTH, glucose, serum cortisol levels, and behaviour scores in horses involved in EAI sessions with military veterans affected by post-traumatic stress disorder (PTSD) and traumatic brain injury compared to sessions with experienced riders and they did not find any significant differences [61]. Similar results were described by Malinowsiki [62] and McKinney [63]: these researchers concluded that no significant differences were detected in delta salivary cortisol levels of horses comparing EAIs to traditional riding lessons or rest.

In our study, we found a significantly smaller increase of adrenaline in ASD sessions compared to TD sessions. Adrenaline is responsible for the immediate response of the sympathetic branch of the ANS to stressors; therefore, this result suggests diminished arousal of the horse in EAI with children with ASD. This lack of arousal may be related to stimulus-evoked expectations resulting from environmental information that the horse receives from the handler, the child, and the overall setting [64]. These animals are employed in EAIs routinely, performing recurring tasks and activities. Therefore, the lack of activation of the sympathetic nervous system in ASD children may be due to a reduced expectation of novelty or an implicit solicitation to restrain their activation by the handler, as they are dealing with a child that needs special attention and care [65]. Lower activation 
of the HPA axis in horses has been suggested also by other researchers [66] investigating neuroendocrine responses during EAIs with children with physical disabilities, compared to recreational riding. In their study, endorphin and ACTH did not show significant changes, while cortisol was lower after EAI sessions. Our HR and HRV data support such hypothesis, providing an insight into the mental state of the animals involved in ASD and TD sessions. Analysing the main spectral components of the frequency domain, we noticed again a dominant vagal tone in ASD sessions compared to TD sessions. Indeed, we highlighted that the LF/HF ratio, which is a marker of sympathetic activity [67] was significantly reduced in the resting phases of the ASD sessions, compared to the TD sessions. Besides, RMMSD values, which represent vagal activity [46], were higher in ASD sessions, reaching a statistically significant difference compared to TD sessions.

In our study, we also investigated eye temperature using infrared thermography-IRT. As this parameter is not influenced by exercise per se, it may be effective in evaluating the activation of the ANS, without being confounded by locomotor activity [68]. According to our results, the horse's eye temperature did not show significant differences between ASD and TD sessions. We only highlighted a peak in the grooming phase compared to baseline, which became significant in ASD sessions, suggesting a physiological response of the animal as it started being groomed at the beginning of the EAI session. The handler gently restrained horses, while children groomed them. Horses were familiar with grooming procedures and they did not show any escape reaction.

It is hard to hypothesize the ultimate physiological significance in the increase of eye temperature, which is probably due to the horse's awareness that the riding session is going to start: the grooming phase may act as a cue [69]. Interpretation of eye temperature changes in animals is still under debate. An increasing number of studies have found correlations between the rise of eye temperature and aversive stimuli and it appears to be indicative of alerting, anxiety, and possible discomfort [70,71]. Meanwhile, other researchers have highlighted that an increase in eye temperature may be related to positive emotional states [44]. In conclusion, IRT may be a useful tool to assess arousal although it fails to discriminate the positive vs the negative emotional content and behavioural cues may be needed to interpret these results [72].

When considering horse behaviours, no significant differences were found between ASD and TD sessions. However, an interesting result was found when analysing stressrelated behaviours during the different phases of each session. In particular, a higher frequency of behaviours indicative of stress was found in the stationary phase, while resting phases, especially mounting and dismounting, appeared as the most challenging for the animal. It is possible to hypothesize that ill-fitted tack, type of handler restraint or children not very experienced with the horse may cause discomfort during mounting and dismounting. We conclude that commonly used behavioural requests in the different phases of the riding session should be managed with much more attention by the horse handler during EAI sessions to avoid stressful situations for the animal.

\section{Limitations of the Study}

The current study was designed to investigate the effects of EAI sessions with children with ASD vs. TD children on the welfare of the horses involved, investigating both physiological and behavioural signals of stress commonly used in equitation science $[15,34-41]$. We acknowledge that the animal sample was very heterogeneous in terms of age, sex, and breeds of the horses enrolled in the study. This point necessarily affected the reliability of haematological and cardiac data [50]. Moreover, in equids, several confounding factors may influence the repeatability and reliability of HRV quantification [73]. Even the transmission of data from the Polar Equine RS800 was not always efficient and eight horses had an incomplete dataset. Environmental conditions affected the quality of IRT images because sessions were performed in outside paddocks.

Lack of information about the long-term anamnesis of the horses involved, especially concerning the training methods used before their involvement in EAI practice and the 
nature of the previous experience they had in EAI, make a harder interpretation of the behavioural data. Horses enrolled in the study were 17 years old on average and it is well known that the use of aversive training methods was very common 10-15 years ago [68]. Moreover, they were assessed only twice, once with a child with ASD and once with a TD child: nowadays, no data are available about the variability of behavioural and physiological responses in horses to different children. Furthermore, we did not code child and handler behaviours performed during sessions including grooming, mounting, and dismounting phases to enhance the understanding of reactions in horses. Therefore, it cannot be ruled out that any difference between groups (ASD vs. TD) may be caused by a difference in IQ.

Currently, researchers have highlighted that lack of control over environmental factors may induce a psychological condition called learned helplessness [68]. The horse can show apathy and may only be compliant with the trainer's requests. Some authors have suggested that learned helplessness may be related to depression-like conditions and anhedonia [39]. Thus, the absence of both conflict behaviour and physiological arousal is not necessarily indicative of a good welfare status [54]. The presence of positive emotions could be used as an important endpoint to assess animal's welfare. Further studies are needed to investigate this aspect.

\section{Conclusions}

In conclusion, stress responses in horses involved in EAI's were not affected negatively by short EAI sessions with ASD children compared to TD children of the same age and experience. Lack of novelty expectation during sessions with ASD children is likely to cause lower sympathetic tone, compared to sessions with TD children, an observation that requires to be studied further for the potential implications on horse's welfare. Moreover, we noticed that some phases of the sessions seem to be more stressful for the horse (e.g., mounting and dismounting phase) requiring special attention by the animal handler. The results of this study appear important to refine methodologies in EAIs, encouraging professionals involved in animal-assisted interventions towards a greater awareness of horse's welfare needs, which could enhance their role as emotional mediators.

Future large-scale studies need to be addressed to investigate positive emotion indicators in horses during EAI sessions and their reactions to human behaviours performed by different people.

Author Contributions: Conceptualization F.C.; methodology M.B., E.V., A.S., F.L., M.T.; investigation L.C., M.D.S., M.B., B.C., E.V., V.R.; Formal analysis M.B., B.C., A.T., M.T., E.V., V.R.; data curation L.C., M.D.S., writing—original draft preparation L.C., M.D.S.; writing—review and editing L.C., F.C., M.B., B.C.; Visualization L.C., M.D.S.; funding administration and acquisition L.C., M.D.S.; Formal analysis M.B., B.C., A.T., M.T., E.V., V.R., R.O., C.V. All authors have read and agreed to the published version of the manuscript.

Funding: This research was funded by the Italian Ministry of Health, grant number RC 2013/13.

Institutional Review Board Statement: The methods and procedures of this study were in accordance with Italian legislation (D.L.vo n. 26 of 4 March 2014) on the protection of animals used for scientific purposes (Authorization $n^{\circ} 1055 / 2015-P R$ ). The research protocol was approved by the Ethics Committees of the Istituto Zooprofilattico Sperimentale delle Venezie (EC protocol number 6/2014) and the Istituto Superiore di Sanità (Prot. PRE-790/15).

Informed Consent Statement: Informed consent was obtained from all subjects involved in the study (see Section 2.1 Ethical Statement).

Data Availability Statement: All relevant data is listed in the manuscript. Additional information can be requested from the authors upon reasonable request.

Acknowledgments: The authors of this study would like to acknowledge the Italian Ministry of Health for funding this research and every individual and organization that contributed to its realization, in particular, the riding Centres: Centro di Riabilitazione Equestre "Vittorio di Capua" 
(ASST Grande Ospedale Metropolitano Niguarda, Milano), A.S.D. Equitazione per tutti (Fiumicino, Roma), Centro Ippico Meisino (Torino), Grande Ranch di San Francesco al Campo (Rivarossa, Torino) and their teams, with special thanks to Roberto Vaccari, Annalisa Roscio and Aurora Sotgiu, Claudia Vinti, Francesca Bisacco and Elena Leoni (EquiOasi Arcadia, Terricciola, Pisa). Special acknowledgments go out to Elena Tamagnone, Silvia Gozzo, Miriam Bottero, and Noémie Pinchaud for helping gather research data.

Conflicts of Interest: The authors declare no conflict of interest.

\section{References}

1. Kendall, E.; Maujean, A.; Pepping, C.A.; Downes, M.; Lakhani, A.; Byrne, J.; Macfarlane, K. A systematic review of the efficacy of equine-assisted interventions on psychological outcomes. Eur. J. Psychother. Couns. 2015, 17, 57-79. [CrossRef]

2. Rigby, B.R.; Grandjean, P.W. The Efficacy of Equine-Assisted Activities and Therapies on Improving Physical Function. J. Altern. Complem. Med. 2016, 22, 9-24. [CrossRef]

3. Borgi, M.; Loliva, D.; Cerino, S.; Chiarotti, F.; Venerosi, A.; Bramini, M.; Nonnis, E.; Marcelli, M.; Vinti, C.; De Santis, C.; et al. Effectiveness of a Standardized Equine-Assisted Therapy Program for Children with Autism Spectrum Disorder. J. Autism. Dev. Disord. 2016, 46, 1-9. [CrossRef]

4. Stergiou, A.; Tzoufi, M.; Ntzani, E.; Varvarousis, D.; Beris, A.; Ploumis, A. Therapeutic Effects of Horseback Riding Interventions: A Systematic Review and Meta-analysis. Am. J. Phys. Med. Rehabil. 2017, 96, 717-725. [CrossRef]

5. Trzmiel, T.; Purandare, B.; Michalak, M.; Zasadzka, E.; Pawlaczyk, M. Equine assisted activities and therapies in children with autism spectrum disorder: A systematic review and a meta-analysis. Complem. Ther. Med. 2019, 42, 104-113. [CrossRef]

6. Winchester, P.; Kendall, K.; Peters, H.; Sears, N.; Winkley, T. The Effect of Therapeutic Horseback Riding on Gross Motor Function and Gait Speed in Children Who Are Developmentally Delayed. Phys. Occup. Ther. Pediatr. 2002, 22, 37-50. [CrossRef]

7. Bass, M.M.; Duchowny, C.A.; Llabre, M.M. The effect of therapeutic horseback riding on social functioning in children with autism. J. Autism. Dev. Disord. 2009, 39, 1261-1267. [CrossRef] [PubMed]

8. Gabriels, R.L.; Agnew, J.A.; Holt, K.D.; Shoffner, A.; Zhaoxing, P.; Ruzzano, S.; Clayton, G.H.; Mesibov, G. Pilot study measuring the effects of therapeutic horseback riding on school-age children and adolescents with autism spectrum disorders. Res. Autism. Spectr. Disord. 2012, 6, 578-588. [CrossRef]

9. Keino, H.; Funahashi, A.; Keino, H.; Miwa, C.; Hosokawa, M.; Hayashi, Y.; Kawakita, K. Psycho-educational Horseback Riding to Facilitate Communication Ability of Children with Pervasive Developmental Disorders. J. Equine Sci. 2009, 20, 79-88. [CrossRef] [PubMed]

10. Kern, J.K.; Garver, C.R.; Mehta, J.; Trivedi, M.H. Prospective Trial of Equine-Assisted Activities in Autism Spectrum Disorder Chronic Mercury Toxicity: Comprehensive Review View Project Brain Network Analysis in Depression View Project. Available online: https:/ / www.researchgate.net/publication/51874213 (accessed on 11 September 2020).

11. Lanning, B.A.; Baier, M.E.M.; Ivey-Hatz, J.; Krenek, N.; Tubbs, J.D. Effects of equine assisted activities on autism spectrum disorder. J. Autism. Dev. Disord. 2014, 44, 1897-1907. [CrossRef] [PubMed]

12. Ward, S.C.; Whalon, K.; Rusnak, K.; Wendell, K.; Paschall, N. The association between therapeutic horseback riding and the social communication and sensory reactions of children with autism. J. Autism Dev. Disord. 2013, 43, 2190-2198. [CrossRef]

13. Christon, L.M.; Mackintosh, V.H.; Myers, B.J. Use of complementary and alternative medicine (CAM) treatments by parents of children with autism spectrum disorders. Res. Autism. Spectr. Disord. 2010, 4, 249-259. [CrossRef]

14. De Santis, M.; Contalbrigo, L.; Borgi, M.; Cirulli, F.; Luzi, F.; Redaelli, V.; Stefani, A.; Toson, M.; Odore, R.; Vercelli, C.; et al. Equine Assisted Interventions (EAIs): Methodological Considerations for Stress Assessment in Horses. Vet. Sci. 2017, 4, 44. [CrossRef] [PubMed]

15. Hausberger, M.; Gautier, E.; Biquand, V.; Lunel, C.; Jégo, P. Could Work Be a Source of Behavioural Disorders? A Study in Horses. PLOS ONE 2009, 4, e7625. [CrossRef]

16. Munsters, C.C.B.M.; Visser, K.E.K.; van den Broek, J.; Sloet van Oldruitenborgh-Oosterbaan, M.M. The influence of challenging objects and horse-rider matching on heart rate, heart rate variability and behavioural score in riding horses. Vet. J. 2012. [CrossRef]

17. Bartolomé, E.; Cockram, M.S. Potential Effects of Stress on the Performance of Sport Horses. J. Equine Vet. Sci. 2016, 40, 84-93. [CrossRef]

18. Waran, N.; Randle, H. What we can measure, we can manage: The importance of using robust welfare indicators in Equitation Science. Appl. Anim. Behav. Sci. 2017, 190, 74-81. [CrossRef]

19. Hausberger, M.; Stomp, M.; Sankey, C.; Brajon, S.; Lunel, C.; Henry, S. Mutual interactions between cognition and welfare: The horse as an animal model. Neurosci. Biobehav. Rev. 2019. [CrossRef]

20. Serpell, J.A.; Coppinger, R.; Fine, A.H.; Peralta, J.M. Welfare Considerations in Therapy and Assistance Animals. In Handbook on Animal-Assisted Therapy; Elsevier Inc.: San Diego, CA, USA, 2010; pp. 481-503. [CrossRef]

21. Hartley, S.L.; Sikora, D.M.; McCoy, R. Prevalence and risk factors of maladaptive behaviour in young children with autistic disorder. J. Intellect. Disabil. Res. 2008, 52, 819-829. [CrossRef]

22. Hirota, T.; Deserno, M.; McElroy, E. The Network Structure of Irritability and Aggression in Individuals with Autism Spectrum Disorder. J. Autism. Dev. Disord. 2020, 50, 1210-1220. [CrossRef] 
23. Fenner, K.; Yoon, S.; White, P.; Starling, M.; McGreevy, P. The Effect of Noseband Tightening on Horses' Behavior, Eye Temperature, and Cardiac Responses. PLoS ONE 2016, 11, e0154179. [CrossRef]

24. Bartolomé, E.; Sanchez, M.; Molina, E.; Schaefer, A.; Cervantes, I.; Valera, M. Using eye temperature and heart rate for stress assessment in young horses competing in jumping competitions and its possible influence on sport performance. Animal 2013, 7, 2044-2053. [CrossRef] [PubMed]

25. Rietmann, T.R.; Stauffacher, M.; Bernasconi, P.; Auer, J.A.; Weishaupt, M.A. The Association between Heart Rate, Heart Rate Variability, Endocrine and Behavioural Pain Measures in Horses Suffering from Laminitis. J. Vet. Med. Ser. A. 2004, 51, 218-225. [CrossRef] [PubMed]

26. McConachie, E.L.; Giguère, S.; Rapoport, G.; Barton, M.H. Heart rate variability in horses with acute gastrointestinal disease requiring exploratory laparotomy. J. Vet. Emerg. Crit. Care 2016, 26, 269-280. [CrossRef] [PubMed]

27. Simonato, M.; De Santis, M.; Contalbrigo, L.; Benedetti, D.; Finocchi Mahne, E.; Santucci, V.U.; Borrello, S.; Farina, L. The Italian Agreement between the Government and the Regional Authorities: National Guidelines for AAI and Institutional Context. People Anim. Int. J. Res. Pract. 2018, 1, 1.

28. May, M.L.; Nolen-Walston, R.D.; Utter, M.E.; Boston, R.C. Comparison of Hematologic and Biochemical Results on Blood Obtained by Jugular Venipuncture as Compared with Intravenous Catheter in Adult Horses. J. Vet. Intern. Med. 2010, 24, 1462-1466. [CrossRef] [PubMed]

29. Reimers, T.J.; Salerno, V.J.; Lamb, S.V. Validation and application of solid-phase chemiluminescent immunoassays for diagnosis of endocrine diseases in animals. Comp. Haematol. Int. 1996, 6, 170-175. [CrossRef]

30. Singh, A.K.; Jiang, Y.; White, T.; Spassova, D. Validation of nonradioactive chemiluminescent immunoassay methods for the analysis of thyroxine and cortisol in blood samples obtained from dogs, cats, and horses. J. Vet. Diagn. Investig. 1997, 9, 261-268. [CrossRef] [PubMed]

31. Froin, H.R. Diagnosis of Equine Cushing's Syndrome by ACTH Measurement; Diagnostic Products Corporation Technical Report; Diagnostic Products Corporation: Los Angeles, CA, USA, 1998.

32. Perkins, G.A.; Lamb, S.; Erb, H.N.; Schanbacher, B.; Nydam, D.V.; Divers, T.J. Plasma adrenocorticotropin (ACTH) concentrations and clinical response in horses treated for equine Cushing's disease with cyproheptadine or pergolide. Equine Vet. J. 2010, 34, 679-685. [CrossRef]

33. Westermann, J.; Hubl, W.; Kaiser, N.; Salewski, L. Simple, rapid and sensitive determination of epinephrine and norepinephrine in urine and plasma by non-competitive enzyme immunoassay, compared with HPLC method. Clin. Lab. 2002, 48, 61-71. [CrossRef]

34. Bachmann, I.; Bernasconi, P.; Herrmann, R.; Weishaupt, M.A.; Stauffacher, M. Behavioural and physiological responses to an acute stressor in crib-biting and control horses. Appl. Anim. Behav. Sci. 2003, 82, 297-311. [CrossRef]

35. Kaiser, L.; Heleski, C.R.; Siegford, J.; Smith, K.A. Stress-related behaviors among horses used in a therapeutic riding program. J. Am. Vet. Med. Assoc. 2006, 228, 39-45. [CrossRef]

36. Rietmann, T.R.; Stuart, A.E.A.; Bernasconi, P.; Stauffacher, M.; Auer, J.A.; Weishaupt, M.A. Assessment of mental stress in warmblood horses: Heart rate variability in comparison to heart rate and selected behavioural parameters. Appl. Anim. Behav. Sci. 2004. [CrossRef]

37. Visser, E.K.; Van Reenen, C.G.; Hopster, H.; Schilder, M.B.; Knaap, J.H.; Barneveld, A.; Blokhuis, H.J. Quantifying aspects of young horses' temperament: Consistency of behavioural variables. Appl. Anim. Behav. Sci. 2001, 74, 241-258. [CrossRef]

38. Fureix, C.; Gorecka-Bruzda, A.; Gautier, E.; Hausberger, M. Cooccurrence of Yawning and Stereotypic Behaviour in Horses (Equus caballus). ISRN Zool. 2011, 2011, 1-10. [CrossRef]

39. Fureix, C.; Beaulieu, C.; Argaud, S.; Rochais, C.; Quinton, M.; Henry, S.; Hausberger, M.; Mason, G. Investigating anhedonia in a non-conventional species: Do some riding horses Equus caballus display symptoms of depression? Appl. Anim. Behav. Sci. 2015, 162, 26-36. [CrossRef]

40. Lesimple, C.; Hausberger, M. How accurate are we at assessing others' well-being? The example of welfare assessment in horses. Front. Psychol. 2014, 5, 21. [CrossRef]

41. Hall, C.; Kay, R.; Yarnell, K. Assessing ridden horse behavior: Professional judgment and physiological measures. J. Vet. Behav. Clin. Appl. Res. 2014, 9, 22-29. [CrossRef]

42. Altmann, J. Observational Study of Behavior: Sampling Methods. Behaviour 1974, 49, 227-266. [CrossRef] [PubMed]

43. Friard, O.; Gamba, M. BORIS: A free, versatile open-source event-logging software for video/audio coding and live observations. Methods Ecol. Evol. 2016, 7, 1325-1330. [CrossRef]

44. Stewart, M.; Stafford, K.J.; Dowling, S.K.; Schaefer, A.L.; Webster, J.R. Eye temperature and heart rate variability of calves disbudded with or without local anaesthetic. Physiol. Behav. 2008, 93, 789-797. [CrossRef]

45. Redaelli, V.; Bergero, D.; Zucca, E.; Ferrucci, F.; Costa, L.N.; Crosta, L.; Luzi, F. Use of Thermography Techniques in Equines: Principles and Applications. J. Equine Vet. Sci. 2014, 34, 345-350. [CrossRef]

46. von Borell, E.; Langbein, J.; Després, G.; Hansen, S.; Leterrier, C.; Marchant-Forde, J.; Marchant-Forde, R.; Minero, M.; Mohr, E.; Prunier, A.; et al. Heart rate variability as a measure of autonomic regulation of cardiac activity for assessing stress and welfare in farm animals-A review. Physiol. Behav. 2007. [CrossRef] 
47. West, B.; Welch, K.; Galecki, A. Linear Mixed Models: A Practical Guide Using Statistical Software. 2014. Available online: https:/ / books.google.com/books?hl=it\&lr=\&id=hjT6AwAAQBAJ\&oi=fnd\&pg=PP1\&dq=West+BT, +Welch+KB,+Galecki+ AT.+Linear+mixed+models:+a+practical+guide+using+statistical+software.+Boca+Raton, +FL,+USA:+Chapman+\%26+Hall/ CRC\%3B+2006.\&ots=QyE9sQCvZg\&sig=UQW-OadoHV33nEzHvmKvleCtIx8 (accessed on 14 September 2020).

48. Dunnett, C.W. Pairwise multiple comparisons in the unequal variance case. J. Am. Stat. Assoc. 1980, 75, 796-800. [CrossRef]

49. Ayala, I.; Martos, N.F.; Silvan, G.; Gutierrez-Panizo, C.; Clavel, J.G.; Carlos Illera, J. Cortisol, adrenocorticotropic hormone, serotonin, adrenaline and noradrenaline serum concentrations in relation to disease and stress in the horse. Res. Vet. Sci. 2012, 93, 103-107. [CrossRef]

50. McDonnell, S.M.; Donaldson, M.T.; Beech, J.; Lamb, S.V.; Schanbacher, B.J.; McFarlane, D. Variation in Plasma Adrenocorticotropic Hormone Concentration and Dexamethasone Suppression Test Results with Season, Age, and Sex in Healthy Ponies and Horses. J. Vet. Intern. Med. 2010. [CrossRef]

51. Kurosawa, M.; Nagata, S.; Takeda, F.; Mima, K.; Hiraga, A.; Kai, M.; Taya, K. Plasma catecholamine, adrenocorticotropin and cortisol responses to exhaustive incremental treadmill exercise of the thoroughbred horse. J Equine Sci. 1998, 9, 9-18. [CrossRef]

52. Ferlazzo, A.; Cravana, C.; Fazio, E.; Medica, P. The different hormonal system during exercise stress coping in horses. Vet. World 2020, 13, 847-859. [CrossRef]

53. Kazmi, S.Z.; Zhang, H.; Aziz, W.; Monfredi, O.; Abbas, S.A.; Shah, S.A.; Kazmi, S.S.; Butt, W.H. Inverse Correlation between Heart Rate Variability and Heart Rate Demonstrated by Linear and Nonlinear Analysis. PLoS ONE 2016, 11, e0157557. [CrossRef] [PubMed]

54. König Borstel, U.; Visser, E.; Hall, C. Indicators of stress in equitation. Appl. Anim. Behav. Sci. 2017, 190, 43-56. [CrossRef]

55. van der Kolk, J.H.; Fouché, N.; Gross, J.J.; Gerber, V.; Bruckmaier, R.M. A comparison between the equine and bovine hypothalamus-pituitary-adrenocortical axis. Domest. Anim. Endocrinol. 2016, 56, S101-S111. [CrossRef]

56. Terada, M.; Momozawa, Y.; Komano, M.; Kusunose, R.; Sato, F.; Saito, T.R. Changes in the heart rate and plasma epinephrine and norepinephrine concentrations of the stallion during copulation. Reprod. Med. Biol. 2005, 4, 143-147. [CrossRef]

57. Hyyppä, S. Endocrinal responses in exercising horses. Livest. Prod. Sci. 2005, 92, 113-121. [CrossRef]

58. Martín-Valero, R.; Vega-Ballón, J.; Perez-Cabezas, V. Benefits of hippotherapy in children with cerebral palsy: A narrative review. Eur. J. Paediatr. Neurol. 2018. [CrossRef]

59. Pritchard, J.C.; Burn, C.C.; Barr, A.R.S.; Whay, H.R. Haematological and serum biochemical reference values for apparently healthy working horses in Pakistan. Res. Vet. Sci. 2009, 87, 389-395. [CrossRef]

60. Sample, S.H.; Fox, K.M.; Wunn, D.; Roth, E.; Friedrichs, K.R. Hematologic and biochemical reference intervals for adult Friesian horses from North America. Vet. Clin. Pathol. 2015, 44, 194-199. [CrossRef] [PubMed]

61. Johnson, R.A.; Albright, D.L.; Marzolf, J.R.; Bibbo, J.L.; Yaglom, H.D.; Crowder, S.M.; Carlisle, G.K.; Willard, A.; Russell, C.L.; Grindler, K.; et al. Effects of therapeutic horseback riding on post-traumatic stress disorder in military veterans. Mil. Med. Res. 2018, 5, 1-13. [CrossRef] [PubMed]

62. Malinowski, K.; Yee, C.; Tevlin, J.M.; Birks, E.K.; Durando, M.M.; Pournajafi-Nazarloo, H.; Cavaiola, A.A.; McKeever, K.H. The Effects of Equine-Assisted Activities Therapy on Plasma Cortisol and Oxytocin Concentrations and Heart Rate Variability in Horses and Measures of Symptoms of Posttraumatic Stress Disorder in Veterans. J. Equine Vet. Sci. 2018. [CrossRef]

63. Mckinney, C.; Mueller, M.K.; Frank, N. Effects of Therapeutic Riding on Measures of Stress in Horses. J. Equine Vet. Sci. 2015, 35, 922-928. [CrossRef]

64. Chamove, A.S.; Crawley-Hartrick, O.J.E.; Stafford, K.J. Horse reactions to human attitudes and behavior. Anthrozoös 2002, 15, 323-331. [CrossRef]

65. Janczarek, I.; Kędzierski, W. Emotional Response to Novelty and to Expectation of Novelty in Young Race Horses. J. Equine Vet. Sci. 2011, 31, 549-554. [CrossRef]

66. Fazio, E.; Medica, P.; Cravana, C.; Ferlazzo, A. Hypothalamic-pituitary-adrenal axis responses of horses to therapeutic riding program: Effects of different riders. Physiol. Behav. 2013, 118, 138-143. [CrossRef]

67. Lorello, O.; Ramseyer, A.; Burger, D.; Gerber, V.; Bruckmaier, R.M.; van der Kolk, J.H.; de Solis, C.N. Repeated Measurements of Markers of Autonomic Tone Over a Training Season in Eventing Horses. J. Equine Vet. Sci. 2017, 53, 38-44. [CrossRef]

68. Hall, C.; Randle, H.; Pearson, G.; Preshaw, L.; Waran, N. Assessing equine emotional state. Appl. Anim. Behav. Sci. 2018, 205, 183-193. [CrossRef]

69. Proops, L.; Walton, M.; McComb, K. The use of human-given cues by domestic horses, Equus caballus, during an object choice task. Anim. Behav. 2010, 79, 1205-1209. [CrossRef]

70. Yarnell, K.; Hall, C.; Billett, E. An assessment of the aversive nature of an animal management procedure (clipping) using behavioral and physiological measures. Physiol. Behav. 2013, 118, 32-39. [CrossRef] [PubMed]

71. McGreevy, P.; Warren-Smith, A.; Guisard, Y. The effect of double bridles and jaw-clamping crank nosebands on temperature of eyes and facial skin of horses. J. Vet. Behav. Clin. Appl. Res. 2012, 7, 142-148. [CrossRef]

72. Travain, T.; Colombo, E.S.; Grandi, L.C.; Heinzl, E.; Pelosi, A.; Previde, E.P.; Valsecchi, P. How good is this food? A study on dogs' emotional responses to a potentially pleasant event using infrared thermography. Physiol. Behav. 2016, 159, 80-87. [CrossRef] [PubMed]

73. van Vollenhoven, E.; Grant, C.C.; Fletcher, L.; Ganswindt, A.; Page, P.C. Repeatability and Reliability of Heart Rate Variability in Healthy, Adult Pony Mares. J. Equine Vet. Sci. 2016, 46, 73-81. [CrossRef] 